\title{
Long-term microleakage trends in access cavities conditioned with phosphoric acid and deproteinizing agent for root-canal-treated teeth: an investigation of fluid filtration and microscopy analysis
}

Eyüboğlu, Tan Frrat ; Türkün, Murat ; Erdilek, Necdet ; Òzcan, Mutlu

DOI: https://doi.org/10.1080/01694243.2016.1155910

Posted at the Zurich Open Repository and Archive, University of Zurich

ZORA URL: https://doi.org/10.5167/uzh-128172

Journal Article

Accepted Version

Originally published at:

Eyüboğlu, Tan Fırat; Türkün, Murat; Erdilek, Necdet; Özcan, Mutlu (2016). Long-term microleakage trends in access cavities conditioned with phosphoric acid and deproteinizing agent for root-canal-treated teeth: an investigation of fluid filtration and microscopy analysis. Journal of Adhesion Science and Technology, 30(14):1574-1584. DOI: https://doi.org/10.1080/01694243.2016.1155910 
Long-term microleakage trends in access cavities conditioned with phosphoric acid and deproteinizing agent for root canal treated teeth:

An investigation of fluid filtration and microscopy analysis

Tan Fırat Eyüboğlu, DDS, PhDa / Murat Türkün, DDS, $\mathrm{PhD}^{\mathrm{b}} /$ Necdet Erdilek, DDS, $\mathrm{PhD}^{\mathrm{c}}$ I

Mutlu Özcan, DDS, Dr.med.dent., PhD ${ }^{a}$

${ }^{a}$ Assistant Professor, Istanbul Medipol University, School of Dentistry, Department of Endodontics, Istanbul, Turkey

${ }^{b}$ Professor, Ege University, School of Dentistry, Department of Restorative Dentistry, Izmir, Turkey

${ }^{c}$ Professor, Ege University, School of Dentistry, Department of Endodontics, Izmir, Turkey

${ }^{d}$ Professor, University of Zurich, Dental Materials Unit, Centre for Dental and Oral Medicine, Clinic for Fixed and Removable Prosthodontics and Dental Materials Science, Zurich, Switzerland

Short title: Microleakage in access cavities of root canal treated teeth 
Correspondance to: Dr. Tan Fırat Eyüboğlu, Department of Endodontics, School of Dentistry, Istanbul Medipol University, Unkapanı, Atatürk Bulvarı, No:27, Fatih 34083, Istanbul, Turkey. Tel: +90-212-453-4848; Fax: +90-212-521-0426. e-mail: tfeyuboglu@yahoo.com

Abstract: This study evaluated the long-term microleakage of access cavities conditioned with phosphoric acid and deproteinizing agents for root canal treated teeth using fluid filtration and microscopical analysis. Occlusal surfaces of extracted human mandibular premolars $(\mathrm{N}=90)$ were removed leaving a $4 \mathrm{~mm}$ coronal length from the cemento-enamel junction. After root canal treatment, the specimens were randomly divided into 4 experimental groups $(n=21)$ and the remaining teeth were used for positive control group (n=6): SB: $35 \% \mathrm{H}_{3} \mathrm{PO}_{4}+$ Adper Single Bond 2; SSB: $35 \% \mathrm{H}_{3} \mathrm{PO}_{4}+5.25 \% \mathrm{NaOCl}+10 \%$ Sodium ascorbate $\left(\mathrm{C}_{6} \mathrm{H}_{7} \mathrm{NaO}_{6}\right)+$ Adper Single Bond 2; XP: 35\% $\mathrm{H}_{3} \mathrm{PO}_{4}+\mathrm{XP}$ Bond; SXP: $35 \% \mathrm{H}_{3} \mathrm{PO}_{4}+5.25 \% \mathrm{NaOCl}+10 \%$ Sodium ascorbate $+\mathrm{XP}$ Bond. All cavities were restored with a resin composite (Filtek Z250). After removing the root filling from the apical side, teeth were subjected to fluid filtration test for 1 week, 6 and 12 months followed by $\times 2500$ thermocycling after 1st week and 6th months each. Data were analyzed using one-way ANOVA and Dunnet T3 tests $(\alpha=0.05)$. SEM analyses were carried out after each microleakage evaluation in 2 random teeth from all groups. Microleakage values in groups SB and XP presented no significant difference in any of the evaluated period $(p>0.05)$. Microleakage results of SXP (0.01665) group showed significant difference compared to XP (0.03377) and SB (0.03049) groups after 12 months. SSB group (0.00901) showed significantly less microleakage among all other groups $(0.01665-0.03377)(p<0.05)$. Prior to endodontic treatment, in access cavities, acid etching with $35 \% \mathrm{H}_{3} \mathrm{PO}_{4}$ followed by the application of $\mathrm{NaOCl}$ and sodium ascorbate completely destroyed the collagen layer, reducing the microleakage and resin-dentin interface degradation up to 12 months.

Keywords: Adhesion, endodontics, fluid filtration, microleakage 


\section{Introduction}

Coronal restorations in endodontically involved teeth play a significant role in the success rate of the overall treatment [0-0]. Several factors affect the survival rate of resin composite coronal restorations such as dentin surface characteristics [0-0], resin-dentin interface [0], type of the bonding agent and composite material [0] as well as intraoral physical and chemical changes [0]. Regarding the adhesion of resin-based materials, dentin depth and the angle between the dentinal tubules and dentin surface affect the bonding ability of the adhesive resins to dentin surface. While in deep dentin, perpendicular angle between dentinal tubules and dentin surface produce a better bonding ability, bonding to superficial dentin with almost horizontal angle between dentinal tubules and dentin surface is less favorable [0-0]. The pulp chamber, that is the deepest part of dentin structure having the largest diameter of dentinal tubules, makes almost perpendicular angle between dentinal tubules and dentin surface $[0,0]$. Hence, the bonding mechanism depends highly on resin tags in dentinal tubules more than the hybrid layer in intertubuler dentin $[0,0]$. In fact, a more uniform and effective resin tag and hybrid layer formation could be achieved in root canal treated teeth due to lack of pulpal pressure $[0,0]$.

Total-etch adhesive systems were reported to present less microleakage results and longer resin tag formation than self-etch ones $[0,0]$. Depending on the bonding mechanism and resin tag formation in the pulp chamber, having no pulpal pressure, degradation of hybrid layer could still take place over time [0]. Several studies focused on destruction of the hybrid layer with sodium hypochlorite $(\mathrm{NaOCl})$ in order to form a more durable resin-dentin interface in combination with total-etch systems [0-0]. Although different bonding systems 
had also been used in those studies, the bonding mechanism of self-etch adhesive systems was contradictory with the aspect of $\mathrm{NaOCl}$ deproteinization of collagen layer, therefore main focus of deproteinization remained on total-etch systems regarding resin dentin interface enhancement $[0,0]$. Yet, it has been later described that this failure was not due to deproteinization effect but to oxidization of $\mathrm{NaOCl}$ and suggested to be neutralized with an antioxidant agent such as sodium ascorbate $[0,0]$.

The major factor affecting in vivo durability is hydrolysis of interfacial components, such as collagen and resin, and subsequent elution of the breakdown products [0]. In order to mimic the intraoral conditions, thermocycling and/or water storage of the specimens are considered essential in laboratory studies to assess the long-term durability of bonding agents $[0,0]$.

The objective of this study was to evaluate the long-term microleakage in access cavities conditioned with phosphoric acid followed by deproteinizing agents using fluid filtration test and microscopical analysis. The null hypothesis tested was that long-term microleakage results at the resin-dentin interface would not show significant difference that are modified either with phosphoric acid only or with subsequent sodium hypochlorite and sodium ascorbate application.

\section{Materials and Methods}

\section{Specimen preparation}

Extracted human mandibular premolars $(\mathrm{N}=90)$ with single root canal were used for this study. All teeth were observed under stereomicroscope (Axiocam MRC, Carl Zeiss, Germany) at x40 magnification for fracture, crack, abrasion, attrition, erosion and any forms of deformities. When any of these were present, they were excluded and replaced with new teeth. All teeth were stored in $1 \%$ thymol solution at $4^{\circ} \mathrm{C}$. 
Occlusal surfaces of all teeth were removed with stainless steel discs under water coolant, leaving a $4 \mathrm{~mm}$ coronal length from the cemento-enamel junction. The occlusal surfaces of all specimens were observed under stereomicroscope (Axiocam MRC) to make sure that no enamel was left on the surface.

The specimens were embedded in putty (Speedex, Coltène/Whaledent, Langenau, Germany) prior to access cavity preparation using a $4 \mathrm{~mm}$ length fissure bur (Diatech, Coltene/whaledent AG, 835-012-4 ML, Altstätten, Switzerland) with a handpiece attached to a parallelometer (Rotaks-Dent Dişçilik Ltd., Istanbul, Turkey). In order to standardize the dentin surfaces, the access cavities were prepared $1 / 3$ of mesio-distal diameter and $1 / 2$ of the bucco-lingual diameter of the crowns using a caliper (Fig. 1).

Root canals were enlarged with Protaper System (Dentsply Tulsa Dental, Tulsa, Oklahoma, USA) with the last-file F3 using an endodontic motor (X-Smart Dentsply Tulsa Dental). Only saline solution was used for irrigation after each instrument $(1.5 \mathrm{cc})$ and for the last irrigation protocol. The root canals were then obturated with only gutta-perchas (ProTaper F3, Dentsply Tulsa Dental) without a root canal paste.

The specimens were randomly divided into 4 groups $(n=21)$ and the remaining 6 teeth were used as a positive control group. Access cavities were prepared according to one of the following protocols:

Experimental groups

Brands, manufacturers and chemical compositions of the materials used in this study are listed in Table 1.

SB: The access cavity was acid etched with $35 \% \mathrm{H}_{3} \mathrm{PO}_{4}(3 \mathrm{M}$ ESPE, St Paul, MN, USA) for $15 \mathrm{~s}$ and rinsed for $10 \mathrm{~s}$. A cotton pellet was used to remove the excess water gently. Adhesive resin (Adper Single Bond 2, 3M ESPE) was applied a thin layer in the cavity and air-thinned gently. It was then photo-polymerized for 20 s (Optilux 501, Kerr, Orange, CA, USA). 
SSB: The access cavity was acid etched with $35 \% \mathrm{H}_{3} \mathrm{PO}_{4}$ for $15 \mathrm{~s}$ and rinsed for $10 \mathrm{~s}$. Then, $5.25 \% \mathrm{NaOCl}$ was applied for $10 \mathrm{~min}$ to remove the collagen fibers. Freshly prepared $10 \%$ sodium ascorbate was applied respectively for $10 \mathrm{~min}$ to neutralize the oxidization effect of $\mathrm{NaOCl}$. Adhesive resin (Adper Single Bond) was applied a thin layer in the cavity, airthinned gently and photo-polymerized for $20 \mathrm{~s}$.

XP: In this group, the access cavity was etched with $35 \% \mathrm{H}_{3} \mathrm{PO}_{4}$ for $15 \mathrm{~s}$ and rinsed for 10 s. A cotton pellet was used to remove the excess water gently. Adhesive resin (XP Bond, Dentsply, DeTrey $\mathrm{GmbH}$, Konstanz, Germany) was applied a thin layer in the cavity, airthinned gently and photo-polymerized for $20 \mathrm{~s}$.

SXP: The access cavity was acid etched with $35 \% \mathrm{H}_{3} \mathrm{PO}_{4}$ for $15 \mathrm{~s}$ and rinsed for $10 \mathrm{~s}$. Then, $\mathrm{NaOCl}(5.25 \%)$ was applied for 10 min to remove the collagen fibers. Freshly prepared $10 \%$ sodium ascorbate was applied respectively for $10 \mathrm{~min}$ to neutralize the oxidization effect of $\mathrm{NaOCl}$. Adhesive resin (XP Bond) was applied a thin layer in the cavity, air-thinned gently and photo-polymerized for $20 \mathrm{~s}$.

Positive control group: In this group, access cavity did not receive any conditioning.

All access cavities, except for the positive control group, were restored with a resin composite (Filtek Z250, 3M ESPE) incrementally. Each layer was photo-polymerized for 20 S.

Composite surfaces at the occlusal part of the specimens were polished with polishing rubbers (Kenda Microfill, Kenda AG, Vaduz, Liechtenstein) for $20 \mathrm{~s}$. The apical $3 \mathrm{~mm}$ root parts of all specimens were removed under water coolant with stainless steel discs. Gates Glidden burs (\#5) were used to remove the gutta-percha gently from the apical, paying attention not to touch the coronal restoration to avoid open pathway for fluid filtration test. Remaining gutta-percha particles close to the restoration were removed gently with a dental probe.

Fluid filtration test 
The specimens were stored in $1 \%$ thymol for 1 week in an incubator at $100 \%$ humidity at $37^{\circ} \mathrm{C}$. All surfaces of the specimens, except for occlusal surface and apical aperture, were covered with two layers of nail polish.

Specimens $(n=15)$ from each group were subjected to fluid filtration corono-apically at 2 bar pressure for 1 week, 6 and 12 months. The stabilization time for each specimen was 10 $\min$. Then, the measurements were carried out four times with 2 min intervals. Microleakage for each specimen was calculated according to the following formula:

$$
\mathrm{Lp}=\frac{\mu 1}{\min \mathrm{x} \mathrm{cm}^{2} \mathrm{xcm} \mathrm{H}_{2} \mathrm{O}} \mathrm{t}
$$

The specimens were then thermocycled after 1 week and 6 months fluid filtration for 2500 cycles each with a sum of 5000 cycles between $5-55^{\circ} \mathrm{C}$ with $20 \mathrm{~s}$ intervals in each bath. Microscopical analysis

The remaining 6 specimens from each group were used for scanning electron microscope (SEM) analyses. The analyses were carried out after each microleakage evaluation with 2 teeth from all groups for each period ( 1 week, 6 and 12 months). The specimens were separated bucco-lingually into two equal parts with a stainless steel disc. The surfaces were grinded with \#800, \#1000 and \#1200 silicone papers under water coolant prior to polish with $3 \mu \mathrm{m}$ particle sized emulsion papers. The specimens were then ultrasonically cleaned in distilled water for 2 min and $5 \% \mathrm{NaOCl}$ and $5 \%$ EDTA were applied for 1 min each in sequence. After storing the specimens in a desiccator for two days, they were gold sputtered at $4 \times 10^{-2}$ milibar pressure. SEM (JEOL-JSM-5200 Tokyo, Japan) images were obtained at $\times 500$ to $\times 5000$ magnification.

Statistical analysis

The data were statistically analyzed (SPSS Software 14.0, Chicago, IL, USA) with one-way ANOVA and Dunnet T3 comparisons. $P<0.05$ was considered to be statistically significant in all tests. 


\section{Results}

Microleakage results

After 1-week and 6 months fluid filtration, SSB group showed had significantly less microleakage than those of other groups $(p<0.05)$ (Table 2, Fig. 2). There was no statistically significant difference between other groups ( $p>0.05)$. After 12 months, again SSB group presented significantly less microleakage than those of the other groups $(p<0.05)$. After 12 months, SXP group also showed significantly less microleakage results than those of SB and XP groups $(p<0.05)$ where the latter two were not statistically significant $(p>0.05)$.

At all time points (1 week, 6 and 12 months), SSB showed significantly less microleakage $(p<0.05)$. While for SSB no significant difference was observed between 6 and 12 months $(p>0.05)$, all other groups presented significantly higher microleakage at 12 months $(p<0.05)$

\section{SEM findings}

After 1 week, SB group presented hybrid layer of $5 \mu \mathrm{m}$ thickness and up to $60 \mu \mathrm{m}$ length of resin tag formation (Fig. 3a). After this period, in the SSB group up to $450 \mu \mathrm{m}$ length of resin tags were evident but no hybrid layer were observed. Lateral branches of resin tags were increased in this group compared to SB group (Fig. 3b). XB group had up to 2.5-5 $\mu$ m thick hybrid layer and up to $1000 \mu \mathrm{m}$ resin tag length. Resin tags were thinner in this group compared to SB and SSB groups (Fig. 3c). On the other hand, in SXP group, up to $1500 \mu \mathrm{m}$ length of resin tags were measured but no hybrid layer was observed. Likewise, in XP group also resin tags that detached from their former dentinal tubules folded over the cross section and formed a reticular appearance. This appearance was denser in SXP than that in the XP group (Fig. 3d). 
After 6 months, direct contact between resin tags and composite resin material was observed in SSB and SXP groups (Fig. 3f, 3h). In XP and SXP groups, the thin structure of resin tag formation was also noteworthy (Fig. 3g, 3h). After 12 months, however, detached areas between hybrid layer and composite material were observed in SB group (Fig. 3i). In SSB group, direct contact between resin tags and composite material were visible (Fig $3 \mathrm{j}$ ). Although generally normal resin tag and hybrid layer formation was observed in XP groups, in some areas weakened resin tag and hybrid layer formation was also observed (Fig. 3k). In SXP and SSB groups resin tags and composite material were in tight contact (Fig. 3I).

\section{Discussion}

This study investigated the long-term microleakage in access cavities conditioned with phosphoric acid followed by the application of deproteinizing agent $\mathrm{NaOCl}$ and sodium ascorbate in combination with adhesive resins and composite resin. Since microleakage results showed significant differences between the experimental groups at the end of 12 months, the null hypothesis could be rejected.

It is well known that bonding resin-based materials to enamel is more stable than to dentin in terms of microleakage $[0,0]$. In this study, in order to prevent the interference of bonding to enamel tissues, all occlusal surfaces were removed and dentin surfaces were exposed. Then, all specimens were controlled at x40 magnification to ensure the presence of dentin on the occlusal surfaces of all specimens. Although it has been concluded in many studies to have an important effect on bonding mechanism and resin-dentin interface characteristics $[0-0,0]$, dentin thickness seemed to be disregarded in some studies $[0,0]$. In that regard, the substrate in this study could be considered as the deep dentin.

The exposed collagen structure in acid etched and bonded collagen fiber layer causes nanoleakage, microleakage and failure of the restoration in time [0]. This exposure was explained to happen by collagen smear layer formation and perturbation of collagen layer 
after acid etching, excessive dehydration of the collagen layer and/or inability of the adhesive resin to penetrate the collagen layer completely $[0,0-0]$. This unpredictability of hybrid layer leaded many researchers to remove the collagen layer completely in order to enhance bonding quality $[0,0]$.

Collagen degradation with $\mathrm{NaOCl}$ has different effects on different depths of dentin. In previous studies, it was noted that in both superficial and deep dentin, $\mathrm{NaOCl}$ application improved bonding quality with increased diameters of resin tags, increased lateral branches in resin tags and enhanced wettability of tubule surfaces $[0,0]$. Lateral branches in peritubuler dentin reaching the intertubuler dentin have been identified in excessive amounts in both superficial and deep dentin [0]. Also, collagen degradation with $\mathrm{NaOCl}$ increased the bond strength of adhesive systems to deep dentin whilst showing no effect on the superficial dentin [0]. In this study, dentin depth and access cavity margins were standardized. Thus, through this route, interference of intertubuler-peritubuler dentin ratios and their possible effect on bonding quality were avoided.

The method employed in this study, fluid filtration technique $[0,33]$, is a microleakage measurement technique with the advantage of repeating observations without destroying the specimens, thus enabling long term evaluation with precise and quantitative results [0]. Fluid filtration technique does not have the disadvantages of dye penetration technique that overestimates leakage due to small size of dye molecules making the test questionable in reliability, reproducibility and clinical relevance [0]. Although bacterial leakage is a very reliable method itself, the invasion of bacteria in the dentinal tubules may result in other pathways for the bacteria to travel rather than the resin-dentin interface [0]. This may have deleterious effects of bacteria and bacterial by-products on resin-dentin interface and ruin the standardization of the specimens for long term evaluation. Therefore, fluid filtration method was chosen for long term repeated evaluation of the same specimens in this study. 
Adhesive resins used in conjunction with total etch system are usually acidic $(\mathrm{pH}: 1-2)$ that cause a self-etching procedure on dentin surfaces with $\mathrm{NaOCl}$ induced collagen degradation, with a thickness of $0.2-0.3 \mu \mathrm{m}$ hybrid layer thickness which cannot be observed via SEM [0]. This hybrid layer increases quality of the resin-dentin interface. Single Bond 2 and XP Bond used in this study are mild acidic adhesives with a pH between 5.5 and 6 . Therefore, minimal interference of second etching ability of the bonding materials could be expected in groups SSB and SXP. Thus, it can be stated that the bonding mechanism solely depended on resin tags.

The strong oxidization effect of $\mathrm{NaOCl}$ was reported to affect the polymerization of adhesive resins, causing failure at the resin-dentin interface $[0,0,0,0]$. In order to neutralize the strong biological oxidization effect of $\mathrm{NaOC}$, the use of anti-oxidants such as $10 \%$ Sodium ascorbate was suggested $[0,0-0]$ which was also practiced in this study after $\mathrm{NaOCI}$ application.

In order to avoid any interference of root canal restorations on the microleakage results, all root canal treatments were completed without a sealer and the remaining gutta-percha was removed from the apex after coronal restorations completed. This set up eases the fit of the specimens for fluid filtration test $[0,0]$. One important aspect in such studies is the time due to the nature of nanoleakage and microleakage formation $[33,0-0]$. In addition to the time factor, to mimic the thermo-mechanical changes in the intraoral environment, specimens were also exposed to thermocycling $[0,0,0]$.

SEM findings, especially after 12 months, demonstrated detached areas between the hybrid layer and composite material in SB group. One reason for this could be the desiccation procedure, which needs to be verified in future studies. Nevertheless, both resin tag formation and resin tag length varied in relation with the applied protocols to condition dentin surfaces in access cavities. 


\section{Conclusions}

From this study, the following could be concluded:

1. In access cavities prior to endodontic treatment, after acid etching with $35 \% \mathrm{H}_{3} \mathrm{PO}_{4}$, application of $5.25 \% \mathrm{NaOCl}$ and $10 \%$ sodium ascorbate completely destroyed the collagen layer, reducing the microleakage and resin-dentin interface degradation up to 12 months.

2. Although deproteinizing agents seemed to reduce the degradation of resin-dentin interfaces, complete sealing could not be achieved in any of the groups and microleakage increased in all groups with time. $\mathrm{NaOCl}$-Single Bond adhesive resin presented the least microleakage compared to $\mathrm{NaOCl}-\mathrm{XP}$ Bond combination.

\section{Clinical Relevance}

Considering microleakage and SEM findings, access cavities prior to endodontic treatment, can be best conditioned with $35 \% \mathrm{H}_{3} \mathrm{PO}_{4}$ followed by $5.25 \% \mathrm{NaOCl}, 10 \%$ sodium ascorbate in sequence before adhesive resin and composite application to decrease microleakage at the resin-dentin interface.

\section{Acknowledgement}

The authors acknowledge that; this study was supported by Ege University Department of Scientific Research Projects (Project No: 2007/DIS/006).

\section{Conflict of interest}

The authors did not have any commercial interest in any of the materials used in this study. 


\section{References}

1. Ray HA, Trope M. Periapical status of endodontically treated teeth in relation to the technical quality of the root filling and the coronal restoration. Int Endod J 1995;28:12-18.

2. Van Meerbeek, Vargas M, Inoue S, Yoshida Y, Peumans M, Lambrechts P, Vanherle G. Adhesives and cements to promote preservation dentistry. Oper Dent 2001;6:119-144.

3. Ng YL, Mann V, Rahbaran S, Lewsey J, Gulabivala K. Outcome of primary root canal treatment: systematic review of the literature - Part 2. Influence of clinical factors. Int Endo J 2008;41:6-31.

4. Lopes GC, Perdigão J, Lopes Mde F, Vieira LC, Baratieri LN, Monteiro S Jr. Dentin bond strengths of simplified adhesives: effect of dentin depth. Compend Contin Educ Dent 2006;27:340-345.

5. Akagawa H, Nikaido T, Takada T, Burrow MF, Tagami J. Shear bond strengths to coronal and pulp chamber floor dentin. Am J Dent 2002;15:383-388. 
6. Sattabanasuk V, Shimida Y, Tagami J. The bond of resin to different dentin surface characteristics. Oper Dent 2004;29:333-341.

7. Van Meerbeek B, Inokoshi S, Braem M, Lambrechts P, Vanherle G. Morphological aspects of the resin-dentin interdiffusion zone with different dentin adhesive systems. J Dent Res 1992;71:1530-1540.

8. Van Meerbeek B, Peumans M, Verschueren M, Gladys S, Braem M, Lambrechts P, Vanherle G. Clinical status of ten dentin adhesive systems. J Dent Res 1994;73:1690-1702. 9. Summitt JB, Robins JW, Hilton TJ, Schwartz RS, dos Santos Jose. Fundamentals of Operative Dentistry, A Contemporary Approach, ed. 3. Illinois: Quintessence Pub Co, Inc. 2006;8:183-260.

10. Pashley DH. Dentin bonding: Overview of the substrate with respect to adhesive material. J Esthet Dent 1991;3:46-50.

11. Pashley DH, Sano H, Ciucchi B, Carvalho RM, Russell CM. Bond strength vs. dentin structure. A modeling approach. Arch Oral Biol 1995;40:1109-1118.

12. Sauro S, Pashley DH, Mannocci F, Tay FR, Pilecki P, Sherriff M, Watson TF. Micropermeability of current self-etching and etch-and-rinse adhesives bonded to deep dentine: a comparison study using a double-staining/confocal microscopy technique. Eur $\mathrm{J}$ Oral Sci 2008;116:184-193.

13. Sauro S, Pashley DH, Montanari M, Chersoni S, Carvalho RM, Toledano M, Osorio R, Tay FR, Prati C. Effect of simulated pulpal pressure on dentin permeability and adhesion of self-etch adhesives. Dent Mater 2007;23:705-713.

14. Owens BM, Johnson WW, Harris EF. Marginal permeability of self-etch and total-etch adhesive systems. Oper Dent 2006;31:60-67.

15. De Munck J, Van Landuyt K, Peumans M, Poitevin A, Lambrechts P, Braem M, Van Meerbeek B. A critical review of the durability of adhesion to tooth tissue: Methods and results. J Dent Res 2005;84:118-132. 
16. Hashimoto $M$, Ohno $H$, Kaga M, Endo K, Sano $H$, Oguchi $H$. In vivo degredation of resin-dentin bonds in human over 1-3 years. J Dent Res 2000;79:1385-1391.

17. Gwinnett AJ. A tissue contribution to interfacial bond strength with acid conditioned dentin. Am J Dent 1994;7:243-246.

18. Wakabayashi Y, Kondou Y, Suzuki K, Yatani H, Yamashita A. Effect of dissolution of collagen on adhesion to dentin. Int J Prosthodont 1994;7:302-306.

19. Rueggeberg FA, Margeson DH. The effect of oxygen inhibition on an unfilled/filled composite system. J Dent Res 1990;69:162-165.

20. Prati C, Chersoni S, Pashley DH. Effect of removal of surface collagen fibrils on resindentin bonding. Dent Mater 1999;15:323-331.

21. Perdigão J, Lopes M, Geraldeli S, Lopes GC, García-Godoy F. Effect of a sodium hypochlorite gel on dentin bonding. Dent Mater 2000;16:311-323.

22. Lai SC, Mak YF, Cheung GS, Osorio R, Toledano M, Carvalho RM, Tay FR, Pashley DH. Reversal of compromised bonding to oxidized etched dentin. J Dent Res 2001;80:19191924.

23. Osorio R, Ceballos L, Tay F, Cabrerizo-Vilchez MA, Toledano M. Effect of Sodium hypochlorite on dentin bonding with a polyalkenoic acid containing adhesive system. J Biomed Mater Res 2002;60:316-324.

24. Pamir T, Türkün M, Kaya AD, Sevgican F. Effect of antioxidant on coronal seal of dentin following sodium-hypochlorite and hydrogen-peroxide irrigation. Am J Dent 2006;19:348352.

25. Gaengler P, Hoyer I, Montag R, Gaebler P. Micromorphological evaluation of posterior composite restorations-a 10-year report. J Oral Rehabil 2004;31:991-1000.

26. Silveira de Araújo C, Incerti da Silva T, Ogliari FA, Meireles SS, Piva E, Demarco FF. Microleakage of seven adhesive systems in enamel and dentin. J Contemp Dent Pract 2006;7:26-33. 
27. Pashley DH, Ciucchi B, Sano H, Horner JA. Permeability of dentin to adhesive agents. Quintessence Int 1993;24:618-631.

28. Pashley DH, Carvalho RM. Dentin permeability and dentin adhesion. J Dent. $1997 ; 25: 355-372$.

29. Okamoto Y, Heeley JD, Dogon IL. Effects of phosphoric and tannic acid on dentine collagen. J Oral Rehab 1991;18:507-512.

30. Perdigão J, Thompson JY, Toledano M, Osorio R. An ultra-morphological characterization of collagen-depleted etched dentin. Am J Dent 1999;12:250-255.

31. Toledano M, Perdigão J, Osorio E, Osorio R. Influence of $\mathrm{NaOCl}$ deproteinization on shear bond strength in function of dentin depth. Am J Dent 2002;15:252-255.

32. Derkson GD, Pashley DH, Derkson ME. Microleakage measurement of selected restorative materials: A new in vitro method. J Prosthet Dent 1986;56:435-440.

33. Wu MK, De Gee AJ, Wesselink PR, Moorer WR. Fluid transport and bacterial penetration along root canal fillings. Int Endod J 1993;26:203-208.

34. Tapsir Z, Aly Ahmed HM, Luddin N, Husein A. Sealing ability of various restorative materials as coronal barriers between endodontic appointments. J Contemp Dent Pract 2013;14:47-50.

35. Camps J, Pashley D. Reliability of the dye penetration studies. J Endod 2003;29:592594.

36. Love RM, Chandler NP, Jenkinson HF. Penetration of smeared or non smeared dentine by streptococcus gordonii. Int Endod J 1996;29:2-12.

37. Sano H, Shono T, Takatsu T, Hosoda H. Microporous dentin zone beneath resinimpregnated layer. Oper Dent 1994;19:59-64.

38. Sano H, Takatsu T, Ciucci B, Horner JA, Matthewa WG, Pashley DH. Nanoleakage: Leakage within the hybrid layer. Oper Dent 1995;20:18-25. 
39. Lai SC, Mak YF, Cheung GS, Osorio R, Toledano M, Carvalho RM, Tay FR, Pashley DH. Reversal of compromised bonding to oxidized etched dentin. J Dent Res 2001;80:19191924.

40. Yiu CKY, Garcia-Godoy F, Tay FR, Pashley DH, Imazato, S, King NM, Lai SCN. A nanoleakage perspective on bonding to oxidized dentin. J Dent Res 2002;81:628-632.

41. Bansal S, Tewari S. Ex vivo evaluation of dye penetration associated with various dentine bonding agents in conjunction with different irrigation solutions used within the pulp chamber. Int Endod J 2008;41:950-957.

42. Belli S, Zhang Y, Pereira PN, Pashley DH. Adhesive sealing of the pulp chamber. J Endod 2001;27:521-526.

43. Ozturk B, Ozer F, Belli S. An in vitro comparison of adhesive systems to seal pulp chamber walls. Int Endod J 2004;37:297-306.

44. Piemjai M, Watanabe A, Iwasaki Y, Nakabayashi N. Effect of remaining demineralised dentine on dental microleakage accessed by a dye penetration: how to inhibit microleakage? J Dent 2004;32:495-501.

45. Derkson GD, Pashley DH, Derkson ME. Microleakage measurement of selected restorative materials: a new in vitro method. J Prosthet Dent 1986;56:435-440.

46. Goldman M, Simmons S, Rush R. The usefulness of dye-penetration studies reexamined. Oral Surg Oral Med Oral Pathol Oral Radiol Endod 1999;67:327-332. 


\section{Captions to tables and figures:}

\section{Tables:}

Table 1. The brands, chemical compositions, manufacturers of the adhesive resins used in this study.

Table 2. Fluid filtration test results as a function of access cavity conditioning method and timepoints. Same lowercase superscript letters in each column and same uppercase letters in each row indicate no significant difference $(p>0.05)$. See Table 1 for group abbreviations.

\section{Figures:}

Fig. 1. Access cavity borders prepared $1 / 3$ of mesio-distal and $1 / 2$ of the bucco-lingual diameter of the premolars.

Fig. 2. Estimated marginal means of fluid filtration test results as a function of access cavity conditioning method and 3 time intervals.

Figs. 3a-I. SEM images of a) SB group (1 week) showing up to $5 \mu \mathrm{m}$ thick hybrid layer and up to $60 \mu \mathrm{m}$ of resin tag length, b) SSB group (1 week) with up to $450 \mu \mathrm{m}$ length of resin tag. Note no hybrid layer formation and increased lateral branches of resin tags compared to SB group, c) XP group (1 week) presenting up to 2.5-5 $\mu \mathrm{m}$ thick hybrid layer and up to $1000 \mu \mathrm{m}$ resin tag length. Note the thinner resin tag structure in this group compared to SB and SSB, d) SXP group (1 week) showing up to $1500 \mu \mathrm{m}$ length of resin tag and no hybrid layer. Similar to XP group, note the detached resin tags from their former dentinal tubules folded over the cross section, forming a reticular appearance, e) SB group (6 months) with intact resin tags and hybrid layer, f) SSB group (6 months) with detached composite resin material from surface. Resin tags were present beneath the former composite material and ended just above the dentinal tubule orifices with no hybrid layer formation, g) XP group (6 
months) with detached composite resin material from the surface. Note the difference between the diameter of resin tags and dentinal tubules, h) SXP group (6 months) with resin tags attached to composite resin material without hybrid layer formation. Note the thinner resin tag structure compared to SB and SSB group, i) SB group (12 months) with detached composite resin material from the hybrid layer, j) SSB group (12 months) with direct contact between resin tags and composite resin material but no hybrid later formation. Note the resin tag integrity even after 12 months, $\mathbf{k}$ ) XP group (12 months) with weakened resin tags and hybrid layer formation. Note the thinner resin tag structure compared to SB and SSB group, I) SXP group (12 months) with detachment of composite resin from the surface. Resin tags and their formation could be observed beneath the former composite material. Note the thinner resin tag structure compared to SB and SSB groups. 
Tables:

\begin{tabular}{|c|c|c|}
\hline Brand & Manufacturer & Chemical composition \\
\hline $\begin{array}{l}\text { Adper Single } \\
\text { Bond } 2 \\
\text { (SB) }\end{array}$ & $\begin{array}{c}\text { 3M ESPE, St. Paul, } \\
\text { MN, USA }\end{array}$ & $\begin{array}{c}\text { bis-GMA, HEMA, dimethacrylates, ethanol, water, photoinitiator } \\
\text { system, methacrylate functional copolymer of polyacrylic and } \\
\text { polyitaconic acids }\end{array}$ \\
\hline $\begin{array}{l}\text { XP BOND } \\
\text { total etch } \\
\text { adhesive } \\
\text { system } \\
\text { (XP) }\end{array}$ & $\begin{array}{l}\text { Dentsply, DeTrey } \\
\text { GmbH, Konstanz, } \\
\text { Germany }\end{array}$ & $\begin{array}{l}\text { Carboxylic acid modified dimethacrylate (TCB resin); Phosphoric } \\
\text { acid modified acrylate resin (PENTA); Urethane Dimethacrylate } \\
\text { (UDMA); Triethyleneglycoldimethacrylate (TEGDMA); 2- } \\
\text { hydroxyethylmethacrylate (HEMA); Butylated benzenediol } \\
\text { (stabilizer); Ethyl-4-dimethylaminobenzoate; Camphorquinone; } \\
\text { Functionalized amorphous silica; t-butanol }\end{array}$ \\
\hline
\end{tabular}

Table 1. The brands, chemical compositions, manufacturers of the adhesive resins used in this study.

\begin{tabular}{|l|c|c|c|}
\hline \multicolumn{1}{|c|}{ Experimental Groups } & $\mathbf{1}$ week & $\mathbf{6}$ months & $\mathbf{1 2}$ months \\
\hline SB & $0.00949^{\mathrm{b}, \mathrm{A}}$ & $0.02111^{\mathrm{b}, \mathrm{B}}$ & $0.03049^{\mathrm{c}, \mathrm{C}}$ \\
\hline $\mathrm{NaOCl}+\mathrm{C}_{6} \mathrm{H}_{7} \mathrm{NaO}_{6}+\mathrm{SB}$ (SSB) & $0.00491^{\mathrm{a}, \mathrm{A}}$ & $0.0083^{\mathrm{a}, \mathrm{B}}$ & $0.00901^{\mathrm{a}, \mathrm{B}}$ \\
\hline $\mathrm{XP}$ & $0.01019^{\mathrm{b}, \mathrm{A}}$ & $0.02626^{\mathrm{b}, \mathrm{B}}$ & $0.03377^{\mathrm{C}, \mathrm{C}}$ \\
\hline $\mathrm{NaOCl}+\mathrm{C}_{6} \mathrm{H}_{7} \mathrm{NaO}_{6}+\mathrm{XP}$ (SXP) & $0.00844^{\mathrm{b}, \mathrm{A}}$ & $0.01477^{\mathrm{b}, \mathrm{B}}$ & $0.01665^{\mathrm{b}, \mathrm{C}}$ \\
\hline
\end{tabular}

Table 2. Fluid filtration test results as a function of access cavity conditioning method and timepoints. Same lowercase superscript letters in each column and same uppercase letters in each row indicate no significant difference $(p>0.05)$. See Table 1 for group abbreviations. 
Figures:

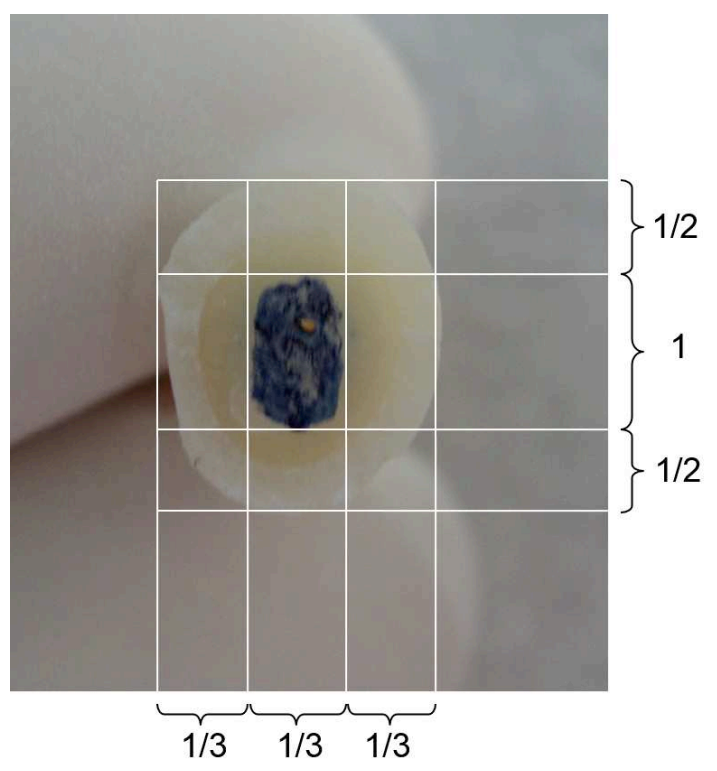

Fig. 1. Access cavity borders prepared $1 / 3$ of mesio-distal and $1 / 2$ of the bucco-lingual diameter of the premolars.

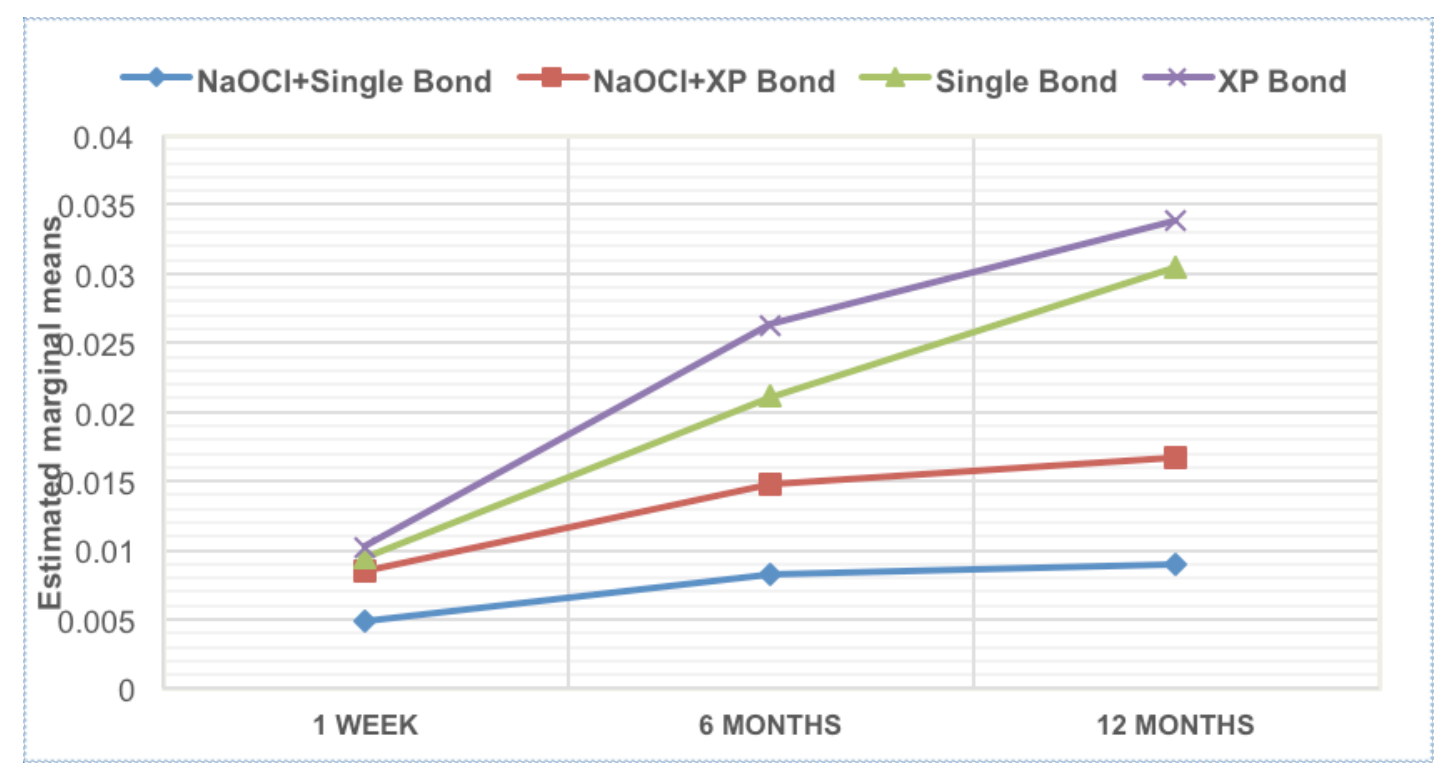

Fig. 2. Estimated marginal means of fluid filtration test results as a function of access cavity conditioning method and 3 time intervals. 


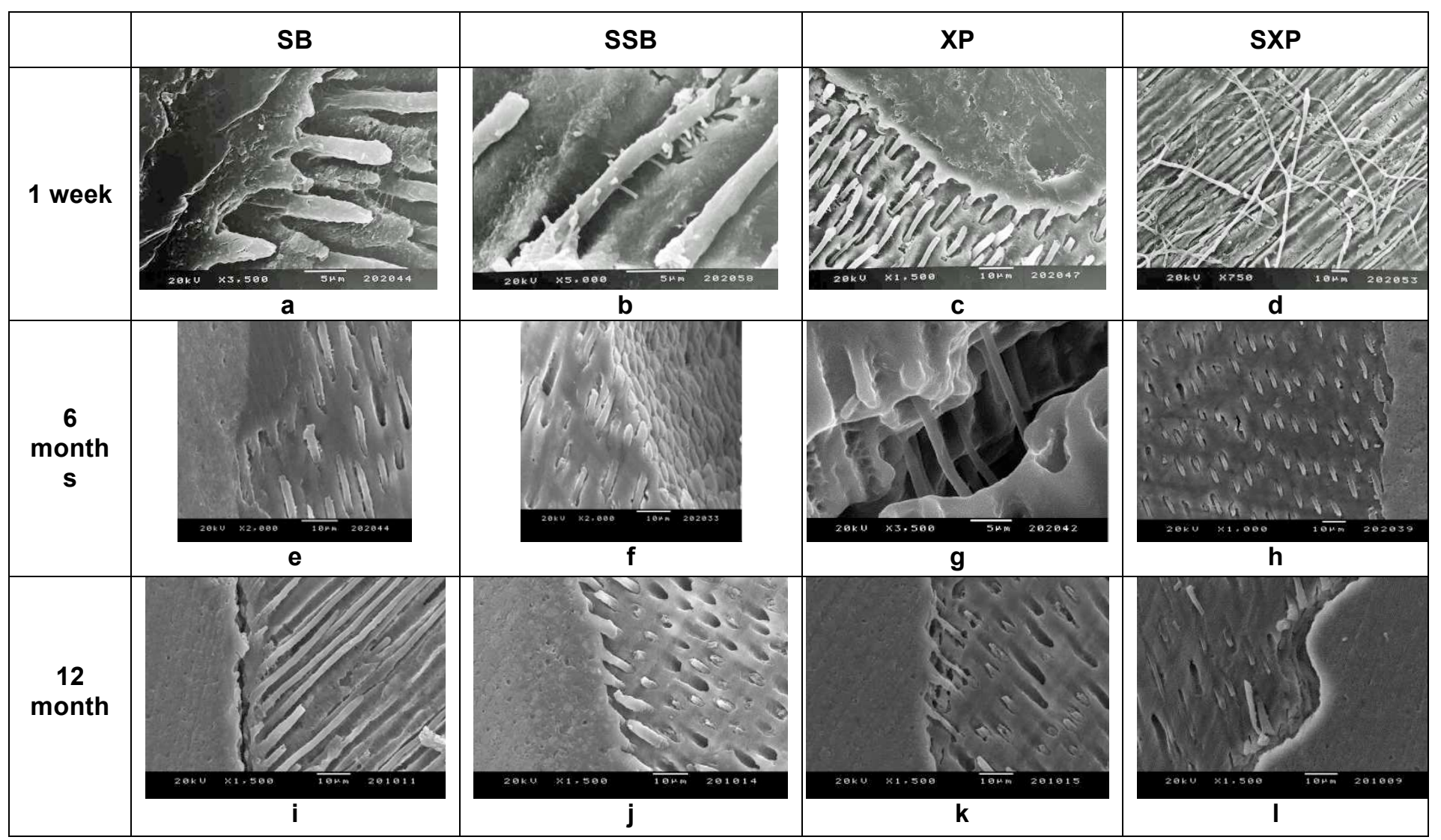

Figs. 3a-I. SEM images of a) SB group (1 week) showing up to $5 \mu \mathrm{m}$ thick hybrid layer and up to $60 \mu \mathrm{m}$ of resin tag length, b) SSB group (1 week) with up to $450 \mu \mathrm{m}$ length of resin tag. Note no hybrid layer formation and increased lateral branches of resin tags compared to SB group, c) XP group (1 week) presenting up to 2.5-5 $\mu \mathrm{m}$ thick hybrid layer and up to $1000 \mu \mathrm{m}$ resin tag length. Note the thinner resin tag structure in this group compared to SB and SSB, d) SXP group (1 week) showing up to $1500 \mu \mathrm{m}$ length of resin tag and no hybrid layer. Similar to XP group, note the detached resin tags from their former dentinal tubules folded over the cross section, forming a reticular appearance, e) SB group (6 months) with intact resin tags and hybrid layer, f) SSB group (6 months) with detached composite resin material from surface. Resin tags were present beneath the former composite material and ended just above the dentinal tubule orifices with no hybrid layer formation, g) XP group (6 months) with detached composite resin material from the surface. Note the difference between the diameter of resin tags and dentinal tubules, h) SXP group (6 months) with resin tags attached to composite resin material without hybrid layer formation. Note the thinner resin tag structure compared to SB and SSB group, i) SB group (12 months) with detached composite resin material from the hybrid layer, j) SSB group (12 months) with direct contact between resin tags and composite resin material but no hybrid later formation. Note the resin tag integrity even after 12 months, k) XP group (12 months) with weakened resin tags and hybrid layer formation. Note the thinner resin tag structure compared to SB and SSB group, I) SXP group (12 months) with detachment of composite resin from the surface. Resin tags and their formation could be observed beneath the former composite material. Note the thinner resin tag structure compared to SB and SSB groups. 
